\title{
College Students' Attitudes Toward Counseling for Mental Health Issues in Two Developing Asian Countries
}

\author{
Angus C.H. Kuok ${ }^{1} \odot$ \\ University of Saint Joseph
}

\author{
Jafar Rashidnia ${ }^{2}$ \\ University of Saint Joseph
}

\begin{abstract}
This study examines 300 college students in Iran and China. It clarifies that students from China have more positive attitudes toward counseling than those from Iran using a quantitative survey with well-established existing scales in the literature. The regression tests show different indictors for college students' attitudes toward mental health counseling in these two developing countries. Anticipated risk has been found as the most negative and powerful predictor of attitudes toward counseling in Iran. Stigma has been found as the most negative and powerful predictor of attitudes toward counseling in China. Implications have been discussed for educational departments and governments to advocate positive evaluations on mental health counseling services.
\end{abstract}

Keywords:

Attitudes toward counseling $\bullet$ Anticipated risk $\bullet$ Stigma $\bullet$ Iranian $\bullet$ Chinese

Gelişmekte Olan İki Asya Ülkesinde Üniversite Öğrencilerinin Ruh Sağlı̆̆ Sorunlarına Yönelik Psikolojik Danışma Tutumları

Öz

Bu çalışma İran ve Çin'deki 300 üniversite öğrencisi üzerinde yapılmıştır. Literatürde desteklenen ölçeklerden oluşan nicel bir anket kullanılan çalışmada Çinli öğrencilerin, psikolojik danışma konusunda İranlılardan daha olumlu tutumlara sahip oldukları bulunmuştur. Regresyon testleri, üniversite ögrencilerinin bu iki gelişmekte olan ülkede ruh sağlığı danışmanlığına yönelik tutumları için farklı göstergelerini incelemiştir. Beklenen risk, İran'da psikolojik danışmaya yönelik tutumların en olumsuz ve güçlü göstergesi olarak bulunmuştur. Çin'de ise, damgalanma psikolojik danışmaya yönelik tutumların en olumsuz ve güçlü göstergesi olarak bulunmuştur. Ruh sağlığı danışmanlığı hizmetleri ile ilgili olumlu değerlendirmeleri savunmaya yönelik olarak eğitim bölümleri ve hükümetler için sonuç ve öneriler sunulmuştur.

Anahtar Kelimeler:

Psikolojik danışmaya yönelik tutum • Beklenen risk • Damgalanma • İranlı • Çinli

\footnotetext{
1 Correspondence to: Angus C. H. Kuok (PhD) Department of Psychology Faculty of Social Sciences University of Saint Joseph, Macao, China. Email: anguskuok@gmail.com

2 University of Saint Joseph, Macao, China.

Citation: Kuok, A. C. H., \& Rashidnia, J. (2019). College students' attitudes toward counseling for mental health issues in two developing Asian countries. Spiritual Psychology and Counseling 4, 67-84. http://dx.doi.org/10.12738/spc.2019.4.1.0056
} 
Humans experience difficulties in coping with life's numerous demands and stressors in the different stages of development throughout life (Erikson, 1995). Among these stages is the period between adolescence and emerging adulthood, when humans encounter more various stressors than other stages such as physical changes, sexual identification, peer pressures, study pressure, seeking intimacy in a relationship, conflicts in being independent, and the transition from school to work (Santrock, 2015). Studies have indicated that humans in this transition period experience various psychologically-related challenges such as a stressful university environment with regards to socioeconomic factors, having to adjust to university culture, and experiencing the pressure of academic performance (Bowman \& Payne, 2011; Flisher, De Beer, \& Bokhorst, 2002; Sennet, Finchilescu, Gibson, \& Strauss, 2003). Therefore, students might experience distress that can lead to poor mental health due to these challenges. However, students in higher education are found to be hesitant and to delay seeking counseling when they encounter stressors and issues related to mental health (Young, 2009).

Cooper, Corrigan, and Watson's (2003) study suggested that the kinds of assistance people ask for vary significantly. People tended to seek assistance from medical professionals, including primary care physicians, nurses, and mental health specialists (i.e., psychiatrists, psychologists, or mental health counselors) or to seek assistance from a generic group of community mentors (i.e., clergy, older friends, and teachers). Moreover, the Asian population is hesitant to consult counselors (Eisenberg, Golberstein, \& Gollust, 2007; Masuda et al., 2009). The hesitancy the Asian population displays may be attributed to myths associated with consulting a counselor or professional in relevant disciplines; they believe that others will think they are crazy (Yang, Phelan, \& Link, 2008). In Asian cultures, families are tight knit, so another family member's advice is often sought and valued for this type of decision making. As Asians live in a collectivistic culture in which people tend to categorize others as in-group or out-group in their community (McCarthy, 2005); in other words, families, close friends, and people from their religion are in the in-group while the rest are in the out-group. Thus, professionals in counseling and mental health services are more likely to fall into the out-group.

In addition, Asian cultures value shame avoidance, hierarchical relationships, and collectivistic orientations, as well as emotional self-control, conformity to norms, family recognition through achievement, filial piety, and humility (Kim, 2007). Asia is a very large continent that encompasses many countries, each sharing common and different values or cultures; for example, just as Iran is Persian and China is Asian, both are developing countries with the largest populations in West and East Asia, respectively. Studies have suggested both Iranian and Chinese culture to be collectivist (Li, Wang, \& Fischer, 2004; Tavakoli, 2013); in other words, their 
attitudes, behaviors, family structure, and well-being are guided by loyalty to one's family. However, they were completely different in terms of religion; nearly $98 \%$ of Iranians are Muslim (Hassan, 2008). Surprisingly, more than 50\% of the Buddhists in the world live in China (Pew Research Center, 2016), but around half of the Chinese are atheists (Washington Post, 2013).

Although seeking and receiving help from counseling could assist in reducing distressing symptoms (Bergin \& Garfield, 1994), only a few people who experience significant distress seek counseling (Boldero \& Fallon, 1995; Carlton \& Deane, 2000; Meehan, Lamb, Saltzman, \& O’Carroll, 1992). Andrews, Hall, Telsson, and Henderson's (1999) study found that more than one in five adults in Australia meet the criteria for a mental health disorder, while $62 \%$ of persons with a mental disorder do not seek any professional help (e.g., counseling) for mental health issues. This striking statistic highlights the fact that many people from an individualistic society hesitate to seek counseling services when encountering mental health-related issues; it would be understandable for people in a collectivistic society (like Iran and China) to have much higher reluctance to seek counseling services due to their daily hassles and burdens. Thus, the present study aims to (1) discover students' attitudes toward counseling in Iran and China and (2) understand the factors related to students' attitudes toward counseling in Iran and China.

\section{Attitudes toward Counseling: Differences between China and Iran}

Attitudes are referred to as either favorable or unfavorable evaluations of objects, people, and events (Robbins \& Judge, 2014). Robbins and Judge also suggested that humans' attitudes help predict behaviors when the attitudes correspond to previous experiences or when one is under social pressure. Kushner and Sher (1989, p. 256) mentioned that seeking counseling for mental health issues has been described as a "potentially difficult, embarrassing, and overall risky enterprise... [that can induce] fear and avoidance in some individuals." Particularly critical to those in collectivistic cultures who seek counseling for mental health issues is that this may not only possibly generate harms for themselves and their family, but also create conflict with religious rituals. That is, if an individual encounters a problem, one tends to go to family members, religious leaders, or elders for advice and support, so a person is often discouraged from using counseling services for religious reasons (McCarthy, 2005). However, due to the religious differences between Chinese and Iranian, the impact of religion on seeking counseling for the Chinese (i.e. they tend to seek help from family) is impossible to be much smaller than that for Iranians (i.e. they seek help from both family and religious friends/leaders). Thus, the first hypothesis, H1, is as follows: Chinese attitudes on counseling for mental health issues are more positive than those among Iranians. 


\section{Possible Factors Related to Attitudes toward Counseling}

Moreover, Kushner and Sher (1989) first conceptualized the act of seeking counseling for mental health issues as a classic approach/avoidance conflict. Approach factors like one's level of distress and desire to reduce that distress maximize the likelihood of seeking counseling services for mental health issues; namely, they have positive attitudes toward counseling. In contrast, avoidance factors like perceived risks minimize the chances of seeking counseling. Thus, these people have conceived avoidance factors about counseling services for mental health issues; namely, they possess negative attitudes toward counseling. In Lee's (2004) study of the intentions for seeking counseling for mental health problems, around $25 \%$ of the respondents mentioned that they would seek counseling while $12 \%$ refused to seek any counseling service. Unfortunately, the percentage of those in emerging adulthood who seek counseling is worse than that for the general population. In Hinderaker's (2003) study on college students' use of counseling services, less than $20 \%$ were willing to seek counseling while more than $50 \%$ were unlikely to seek counseling.

Vogel, Wester, and Larson's (2007) review of people avoiding counseling stated the importance of understanding more about the factors that contribute to avoidance when people need to decide on seeking counseling services for mental health issues. They also pointed out that, although several studies exist on the impact of different avoidance factors, most had looked at only one or two factors at a time. Thus, clarifying the relationships among the different avoidance factors involved in whether or not people seek counseling service is necessary and could provide a clearer picture if the factors influencing one's assessment of counseling services were understood. In an effort to contribute to exploring these issues, Vogel, Wester, and Larson (2007) included a large number of the avoidance factors suggested in previous research; namely, stigma, anticipated risk, self-disclosure, treatment, fears, and fear of emotions.

Stigma. Stigma is defined as the fear of being labeled negatively if one seeks counseling assistance for mental health problems (Deane \& Chamberlin, 1994). In other words, a person who seeks counselors considers him/herself less socially acceptable (Corrigan, 2004). Stigma associated with receiving treatment is identified as a major barrier to seeking counseling services (Stefl \& Prosperi, 1985). In addition, some studies have found that people who had sought counseling assistance were negatively labeled as awkward, cold, defensive, dependent, insecure, sad, unsociable, disturbed, crazy, and weak, for example (Sibicky \& Dovidio, 1986). Therefore, imagining that people hesitate to seek counseling services is easy because they consider themselves to be less socially acceptable. Thus, the second hypothesis, H2, is as follows: The more stigma people perceive, the more negative attitudes toward counseling (a) students in Iran and (b) students in China have. 
Anticipated risk. Anticipated risk refers to an individual's perception of the potential dangers of participating in counseling (Vogel \& Wester, 2003). Fisher, Goff, Nadler, and Chinsky (1988) stated the potential danger of opening up to others could be worse than their actual problem. For example, some traditional people tend to avoid counseling because of a culture where seeking help is considered inappropriate (Brooks, 1998). Keith-Lucas (1994) suggested that anticipated risk is likely to be particularly salient for those considering counseling related to divulging distressing or emotional information; people feel vulnerable in front of an expert and consider the potential risk of being hurt further if they feel "misunderstood, ..., judged, or even ignored when they selfdisclose" (Harris, Dersch, \& Mital, 1999, p. 407). Counseling is a type of interpersonal relationship (Teyber, 2005) that can influence one's evaluation of the prospect of seeking help (Vogel \& Wei, 2005). Lin's (2002, p.207) study suggested people often avoid counseling because of the "shame and embarrassment of sharing problems with relative strangers." Therefore, this leads them to view counseling as a risky endeavor and thus to think less about how counseling benefits them. Thus, the third hypothesis, $\mathrm{H} 3$, is as follows: The more people anticipate risk, the more negative attitudes toward counseling (a) students in Iran and (b) students in China have.

Self-disclosure. Self-disclosure occurs "when A knowingly communicates to $B$ information about $A$ which is not generally known and is not otherwise available to B" (Worthy, Gary, \& Kahn, 1969, p. 59). Jourard (1964) first described how the ability to self-disclose to others was central to people's decision to seek help because, during the process of being helped, people had to choose to reveal to others their private feelings, thoughts and attitudes. Self-disclosure is believed to lead to health benefits because of the reduction in distress engendered by confronting a previously concealed stressor (Pennebaker, 1997). Although further studies have reported that personal comfort in self-disclosing to counselors is associated with the intention to seek assistance (Vogel \& Wester, 2003; Vogel et al., 2007), Morton (1978) found that people disclose more to friends than strangers.

Moreover, Komiya, Good, and Sherrod (2000) concluded that Asian peoples' apprehensions about experiencing and disclosing negative emotions are the greatest barriers to seeking counseling. Diala et al. (2000) also reported that people who are uncomfortable talking about personal issues with professionals in mental health care are five times less likely to seek assistance. Quite critically, people in collectivistic societies disclose to their family and friends, whom they perceive as trustworthy, but choose to not disclose to counselors (McCarthy, 2005). Therefore, people who are comfortable in disclosing their distress to family and friends are less likely to seek counseling. Thus, the fourth hypothesis, H4, is: The more people are willing to disclose their problems to family and friends, the more negative attitudes toward counseling (a) students in Iran and (b) students in China have. 
Treatment fear. Treatment fear is defined as "a subjective state of apprehension arising from aversive expectations surrounding the seeking and consuming of mental health services" (Kushner \& Sher, 1989, p. 251). These fears are categorized into three aspects: (1) how the professionals in mental health care would treat the people who seek help, (2) what the professionals in mental health care would think of the people who seek help, and (3) whether the people who seek help would be coerced by the professionals in mental health care. Kushner and Sher (1989) also claimed that fearful responses to actual or even imagined aspects of seeking counseling services might increase one's reluctance to seek assistance. Pipes, Schwarz, and Crouch (1985) found that individuals who did not use counseling facilities have more fears of seeking counseling services. Furthermore, Deane and Todd (1996) also found that treatment fears negatively predict college students' intentions to seek professional assistance. In Chang's (2008) study on Chinese respondents, the unfamiliarity with the counseling process is a major barrier to seeking counseling services. Moreover, Kushner and Sher (1989) found that people who need but have not sought counseling assistance have the highest level of treatment fears, suggesting that these might inhibit their intention to seek counseling services even if they admit that benefits exist. This seems to reflect an idea that people might perceive the act of seeking counseling services detrimentally. Therefore, the thought of seeking counseling services with this negative perception might be perceived as worse than the problem. Thus, the fifth hypothesis, H5, is as follows: The more people perceive treatment fears, the more negative attitudes toward counseling (a) students in Iran and (b) students in China have.

Fear of Emotions. Komiya, Good, and Sherrod (2000) defined this as a fear generated by strong emotions when discussing one's experiences, which might lead the individual to avoid seeking counseling services. Greenson (1987) asserted that a resistance to seeking assistance forms from one's fear of experiencing further hurtful consequences. Moreover, Kelly (1988) found a number of psychotherapy clients to keep secrets from their therapists because telling one's secrets to others induces strong emotions that, being afraid to express them, the individual therefore avoids expressing in session. This is especially true in Asian cultures, where emotional control is highly valued and expression of emotions is perceived as an unfavorable personality trait (Narikiyo \& Kameoka, 1992). Moreover, Vogel and Wester (2003) found that the expectation of having to express emotions to counselors reduces one's positive attitudes toward counseling. Thus, the sixth hypothesis, H6, is: The more one perceives the fear of having to expose emotions, the more negative attitudes toward counseling (a) students in Iran and (b) students in China have.

Aside from the avoidance factors suggested by Vogel, Wester, and Larson (2007), this study also has applied the personality theory, a personality guide on how individuals understand, interpret, and react to the world around them (McCrae \& 
John, 1992). The Big Five is one of the favorite personality models and includes openness, conscientiousness, extraversion, agreeableness, and neuroticism (McCrae \& Costa, 2008; McCrae \& John, 1992). This study targets mainly college students, as they have more opportunities than the general population to learn the real concepts of counseling and mental health services. Therefore, the personality variable of openness has been suggested for determining the relationship of attitudes toward counseling; in other words, people who are willing to experience new things are more likely to have a positive assessment of counseling and similar services. Another reason for choosing openness is that it is a variable related to positive psychology, which focuses on personal strengths and functioning (Seligman \& Csikszentmihalyi, 2000).

Openness. This includes traits like being insightful, imaginative, and possessing a wide variety of interests (Goldberg, 1993; McCrae \& John, 1992). People who like to learn new things and enjoy new experiences usually score high in openness. Seeking counseling is relatively new to people in collectivistic cultures; Chinese and Iranian people who seek help from professionals lead their family and themselves to lose face and perhaps be in conflict with religious rituals. Therefore, those with high openness levels are more likely to seek counseling. Thus, the seventh hypothesis, H7, is: The more one has openness to experiences, the more positive attitudes toward counseling (a) students in Iran and (b) students in China have.

\section{Method}

\section{Respondents}

Three hundred college students (150 Iranian and 150 Chinese) participated in this study as the respondents. Of the 150 Iranian respondents (69 females and 81 males), the average age is 24.54 ranging from 20-25 years old $(S D=3.90)$. All are Muslims. Of the 150 Chinese respondents ( 74 females and 76 males), the average age is 25.19 , ranging from 20-26 years old $(S D=4.42)$. For religion, $140(90 \%)$ are atheist and the rest are Buddhist.

\section{Measures}

Data have been obtained using a questionnaire combining measures from existing scales with established validities and reliabilities; content validity suggests that they were developed according to the corresponding theories (Sekaran \& Bougie, 1992). As all scales were originally developed in English and the study takes place in Iran and China where Persian and Chinese are the respective mother tongues, the scales were first translated by a group of bilingual experts proficient in either both English and Chinese or both English and Persian. Then another group of bilingual experts translated the respective Chinese and Persian versions back to English for comparing 
the similarity. For the main variables, unless otherwise noted, respondents have been asked about the extent to which they agree that the statements describe them. All items use a five-point Likert-type scale ranging from 1 (strongly disagree) to 5 (strongly agree). All the reliabilities of the study's variables are shown in Table 1.

Attitudes toward seeking counseling. This construct was measured by a 10item scale on attitudes toward seeking professional help for psychological problems (Fischer \& Farina, 1995). For the items, the word professional help was replaced with counseling for mental health issues. The original alpha of this scale is .85 (Fischer \& Farina, 1995). Respondents' having higher scores in this measure suggests that they have more positive attitudes toward seeking counseling.

Stigma. This variable is measured by the Self-Stigma of Seeking Help Scale, a 10-item scale whose original alpha value is .72 (Vogel, Wade, \& Haake, 2006). Respondents' having higher scores in this measure suggests that they have higher stigma levels for seeking help.

Anticipated risk. This construct is assessed through Vogel and Wester's (2003) Disclosure Expectation Scale (DES), which consists of two subscales: anticipated risk and anticipated utility. Each subscale is comprised of four items; the four from anticipated utility are the reserved items. The original alpha of this scale was reported to range from .74 to .83 . Respondents' having higher scores in this measure suggests that they perceive higher levels of anticipated risk for disclosure.

Self-disclosure. This variable is assessed using the 12-item Distress Disclosure Inventory (DDI) developed by Kahn and Hessling (2001). The original alpha of this scale is .80 . Respondents' having higher scores in this measure suggests that they are more willing to disclose.

Treatment fear. This variable is measured using a 9-item scale, the Thoughts About Psychotherapy Survey (TAPS) by Kushner and Sher (1989) and adapted from Pipes, Schwarz, and Crouch's (1985) Thoughts About Counseling Scale. Items from TAPS's two subscales, therapist responsiveness and coercion concern, have been combined in the present study. The original alpha of this scale was reported to range from .87 to .92 (Kushner \& Sher, 1989). Respondents' having high scores in this measure suggests that they perceive higher levels of treatment fear.

Fear of emotions. This variable is measured using the 5-item anxiety subscale from the Affective Control Scale (Williams, Chambless, \& Ahrens, 1997), whose original alpha is .94. Respondents' having higher scores on this measure suggests that they perceive higher levels of fear of emotions. 
Openness. This variable is measured using the 5-item Openness to Experience Scale (Golberg, 1999), the original alpha for this scale is .86. Respondents' having higher scores in this measure suggests that they are more willing to try new things.

\section{Procedure}

As the target group of this study is university students in Iran and China, the data have been obtained in districts near universities in Tehran, Iran, and Macau, China. In addition, this study has not been conducted inside university campuses where the respondents study to avoid any pressure from peers or teachers. The systematic sampling method has been used where every fifth person passing by was approached to be a respondent when they were on lunch break or after school, as this helps ensure the respondents have more spare time to fill in the questionnaire and, by not taking place within the universities, to eliminate the sense of being monitored by their peers. In Iran, those who agreed to participate were handed the questionnaire; of the 221 people asked, 150 completed questionnaires have been collected with a response rate of $67.9 \%$. In China, 196 agreed to participate with 150 completed questionnaires being collected with a response rate of $76.5 \%$.

\section{Compliance with Ethical Standards}

In accord with international guidelines for the ethical treatment of research participants, the guidelines from the American Psychological Association have been followed. The respondents were approached individually and asked if they were university students, then they were asked for their informed consent and willingness to fill in a questionnaire by telling them the purpose of the study. No conflict of interest has been found for this study.

\section{Results}

\section{Test for Multicollinearity}

This was assessed using a tolerance test $\left(1 R^{2}\right)$ for each independent variable. According to Hair et al. (1998, pp. 191-193), a tolerance value of less than 0.10 is problematic. This test uses all the independent variables (for the planned regressions), and each one is regressed over all the other independent variables (excluding demographics because they are naturally correlated). The tolerance values for the independent variables range from .28 to .70 , all above the .10 cut-off indicating multicollinearity is not a concern. 


\section{Test for Common Method Bias}

Common method bias is a statistical phenomenon in which statistical relationships may be based on the measurement method but not on the measure of the construct. This has been assessed by factor analyzing all the variables in this study together and using the maximum-likelihood approach with a forced, one-factor solution (see Harman, 1960). A ratio of the resultant $\chi^{2}$ value over the degrees of freedom less than 2.00:1 indicates common-method bias (i.e., a single factor). For this study, the ratio was $32.62: 1$, suggesting that common-method bias is not a concern.

\section{Attitudes toward Counseling between Iranian and Chinese Students}

Both students in Iran and China have positive attitudes toward counseling ( $M=$ $4.51, S D=.26$ for the Chinese; $M=4.26, S D=.39$ for the Iranian). As mentioned in the method section, all scales measure between one and five with 3 being the midpoint for scoring. Thus, a score greater than three suggests that the respondent has positive attitudes toward counseling. In addition, an independent samples $t$-test was run on the overall difference between the two means for attitudes toward counseling for mental health issues. Chinese students hold more positive attitudes toward counseling than Iranian students $\left(t_{(298)}=6.677 p<.05\right)$, which supports $\mathrm{H} 1$.

\section{Correlations Analyses}

Means, standard deviations, and correlations have been computed for the variables to assess their hypothesized relationships with attitudes toward counseling. For Iranians, attitudes toward counseling is found to have significant positive and negative correlations to stigma, anticipated risk, treatment fear, and openness; this support H2a, H3a, H4a, H5a, and H7a. However, no significant relationship has been found for fear of emotions, which does not support H6a. For the Chinese, their attitudes toward counseling have been found to have significant positive and negative correlations to all independent variables; this supports $\mathrm{H} 2 \mathrm{~b}$,

Table 1

Inter-correlations between Muslim and Atheist Attitudes toward Counseling and Other Independent Variables in Iran and China.

\begin{tabular}{|c|c|c|c|c|c|c|c|}
\hline & \multicolumn{3}{|c|}{ Muslim in Iran } & \multicolumn{3}{|c|}{ Atheist in China } & \multirow{2}{*}{ Alpha } \\
\hline & Mean & $S D$ & Pearson Correlation & Mean & $S D$ & Pearson Correlation & \\
\hline $\begin{array}{l}\text { 1.Attitudes toward } \\
\text { counseling }\end{array}$ & 4.26 & 0.39 & & 4.51 & 0.26 & & .77 \\
\hline 2.Stigma & 1.69 & 0.39 & $-.76^{* * * *}$ & 1.56 & 0.44 & $-.65 * * * *$ & .84 \\
\hline 3.Anticipated risk & 1.70 & 0.57 & $-.74 * * * *$ & 1.51 & 0.57 & $-.57 * * * *$ & .90 \\
\hline 4.Self disclosure & 3.25 & 1.35 & $-.21 *$ & 3.54 & 1.34 & $-.43 * * * *$ & .98 \\
\hline 5.Treatment fear & 1.59 & 0.28 & $-.60 * * * *$ & 1.49 & 0.51 & $-.57 * * * *$ & .82 \\
\hline 6. Fear of Emotions & 3.50 & 1.10 & -.12 & 3.62 & 1.04 & $-.24 * * *$ & .90 \\
\hline 7.Openness & 3.79 & 0.72 & $.19 *$ & 3.93 & 0.84 & $.43 * * * *$ & .90 \\
\hline
\end{tabular}

Note. All variables are scored from 1 to $5 .{ }^{*}=\mathrm{p}<.05,{ }^{* *}=\mathrm{p}<.01,{ }^{* * *}=\mathrm{p}<.005,{ }^{* * * * *}=\mathrm{p}<.001$. 
$\mathrm{H} 3 \mathrm{~b}, \mathrm{H} 4 \mathrm{~b}, \mathrm{H} 5 \mathrm{~b}, \mathrm{H} 6 \mathrm{~b}$ and $\mathrm{H} 7 \mathrm{~b}$. The details on these results with their relationship strengths are shown in Table 1.

\section{Regression Analysis}

To test the strengths of the relationships among the variables, two multiple stepwise regressions were conducted for Iranian and Chinese attitudes toward counseling.

For Iranian attitudes toward counseling, two variables have been proven to be good predictors. Each predictor has the power to estimate attitudes toward counseling; the impact and effect size $\left(f^{2}\right.$; see Cohen, 1992) of each predictor variable has been measured, and the strongest significant negative predictor is anticipated risk $\left(\Delta R^{2}=.55\right.$ with a large $\left.f^{2}=1.22, p<.001\right)$. The second strongest significant negative predictor is stigma $\left(\Delta R^{2}=.08\right.$, a small $\left.f^{2}=0.09, p<.001\right)$. These variables were combined to form a powerful predictor $\left(R^{2}=.63, F=125.12, p<.001\right)$. These results are shown in Table 2 .

For Chinese attitudes toward counseling, five variables have been found to be predictors. The strongest significant predictor (negative) is stigma $\left(\Delta R^{2}=.42\right.$, a large $f^{2}=0.72, p<.001$ ). The second strongest significant predictor (positive) is openness $\left(\Delta R^{2}=.05\right.$, a small $\left.f^{2}=0.05, p<.001\right)$. The third strongest significant predictor (negative) is treatment fear $\left(\Delta \mathrm{R}^{2}=.02\right.$, a small $\left.f^{2}=0.02, p<.05\right)$. The fourth strongest significant predictor (negative) is self-disclosure $\left(\Delta R^{2}=.02\right.$, a small $f^{2}=0.02, p<$ $.05)$. The fifth strongest significant predictor (negative) is fear of emotions $\left(\Delta R^{2}=.02\right.$, a small $\left.f^{2}=0.02, p<.05\right)$. These variables form a powerful overall predictor $\left(R^{2}=.53\right.$ $F=32.36, p<.001)$. These results are shown in Table 2 .

Table 2

Stepwise Regressions Using the Antecedent Variables as Predictors for Iranian and Chinese Attitudes toward Counseling.

\begin{tabular}{|c|c|c|c|c|c|c|}
\hline \multirow[t]{2}{*}{ Criteria/Variables } & \multicolumn{3}{|c|}{ Iranian Attitudes toward Counseling } & \multicolumn{3}{|c|}{ Chinese Attitudes toward Counseling } \\
\hline & Beta & t-value & $\Delta \mathrm{R}^{2}$ & Beta & t-value & $\Delta \mathrm{R}^{2}$ \\
\hline Stigma & -.291 & $-5.65 * * * *$ & .09 & .092 & $-3.34 * * * *$ & .42 \\
\hline Anticipated risk & -.422 & $-5.60 * * * *$ & .55 & -.095 & -0.79 & \\
\hline Self disclosure & -.001 & -0.01 & & -.067 & $-3.33^{*}$ & .02 \\
\hline Treatment fear & -.067 & -1.30 & & -.122 & $-2.74 *$ & .02 \\
\hline Fear of Emotions & -.130 & -1.94 & & -.064 & $-2.52^{*}$ & .02 \\
\hline Openness & .039 & 0.76 & & .070 & $3.23 * * * *$ & .05 \\
\hline Total $R^{2}$ & & & 63 & & & .53 \\
\hline Final $F$ & & & $125.12 * * * *$ & & & $32.36 * * * *$ \\
\hline$(d f)$ & & & $(2,147)$ & & & $(5,144)$ \\
\hline
\end{tabular}




\section{Discussion}

\section{Iranian and Chinese Students' Attitudes toward Counseling}

A statistically significant difference has been found regarding students' attitudes toward counseling between people in Iran and in China. The participants from China score significantly higher in attitudes toward counseling compared to those from Iran. Religion could be one of the possible explanations for this variation; in this study, all participants from Iran have religious beliefs while $90 \%$ of the participants from China are atheist. Religious individuals prefer talking to their friends and family before making the step to seek counseling (Wamser, Vandenberg \& Hibberd, 2011), even if they want to undertake counseling services, they prefer counselors with the same belief system because they feel there would be greater improvement when working with a therapist who understands and supports their values (Morrow, Worthington, \& McCullough, 1993).

\section{Factors Affecting Iranian and Chinese Students' Attitudes toward Counseling}

This study provides some insights into the attitudes toward counseling of two Asian societies (Iran and China). Namely, different patterns of predictors have been found between the Iranian and Chinese students' attitudes toward counseling. For Iranians, how they interpret the risk they may receive for seeking counseling is the key issue influencing unfavorable evaluations on counseling among Iranian students. When individuals weigh the risks from disclosing one's problem to a counselor and the possible further problems associated with it, they would rather keep their problems to themself. Unlike talking to family members, Muslim clerics, or even Muslims' God, individuals did not feel they would face any negative consequences due to the rules and rituals of religion. Moreover, in collective culture, the uncertain consequences of decision-making (e.g., seeking counseling for mental health issues) not only affects the individual but also generates an impact on family members and close friends (Pearson, 1993); this further increases negative evaluations on counseling.

For the Chinese, stigma is the strongest predictor of attitudes toward counseling, suggesting that individuals' worrying about being labeled negatively for seeking counseling may be a reflection of their weakness and uselessness; this is a major concern among Chinese living with traditional Chinese values. One of these critical values is face, referred to as social reputation, respectability, or the way one is regarded in society (see Ho, 1976). Also in Chinese practice, people would prefer to enhance and save face rather than lose face (see Bond \& Hwang, 1986). Therefore, seeking help from a counselor may be considered an act of losing face (i.e., a public embarrassment, a portrayal of weakness). Moreover, Bond and Hwang (1986) suggested that the Chinese not only want to enhance, save, and not lose one's own face but also want to enhance, save, and not lose others' faces. The Chinese proverb "family scandal should 
not be made public," means family problems and weaknesses should be dealt with in the family, remaining private to avoid losing family face (Pearson, 1993).

Interestingly, the personality variable of openness has been found to predict positive attitudes toward counseling among the Chinese, suggesting that people who are open to experience new things and ideas are more likely to seek counseling service, even if they live in a collectivist society where social harmony is a cultural value of utmost importance (Yang, 1995). In other words, they tend to seek counseling without being encouraged by their culture. Also, for the point of view on religion, atheists do not have the boundary of religious rituals, which lead to conflicts in their thinking and behaviors.

\section{Implications}

The various predictors for Iranian and Chinese attitudes toward counseling have revealed the need for different approaches in these two Asian societies. For Iranians, educating people on the benefits of seeking counseling services is needed. Subjects related to mental health and care can be added to secondary-school education programs. Namely, some education relevant to the main symptoms of different mental health issues would be necessary, but not explaining all the different illnesses along with the criteria of the DSM-IV. The purpose of this would be to increase awareness of different mental health issues based on accurate information rather than on information from misleading sources (e.g., information from peers or the Internet). This would reduce misunderstandings between mental illnesses and common illnesses. For some severe illnesses, teaching them some of the symptoms of the illnesses (i.e., pathology) would be necessary, but not teaching them how the illnesses formed (i.e. etiology). This would minimize the justification of abnormality due to misunderstandings about unusual symptoms or to generalizing the idea of having mental health problems as being the same as some common illnesses (i.e., if someone catches a cold, they have fever and sore throat, or that someone with depression has moods that might swing from extremely subdued to manic). In addition, because religion is crucial to Iranians (McCarthy, 2005), they prefer to ask for help from religious people rather than psychological professionals (counselors). Thus the best way is to equip religious people with a vanguard of knowledge on mental health and advocate them to share the concept of mental health within their social network, preferably with those having the same religious background. Even if people within the religious network do not look first for psychological professionals, at least they can seek help and be more likely to receive accurate information from the representative group of religious people.

For the Chinese, reducing the stigmatization associated with seeking counseling is a very critical issue; people need to understand more about the processes of 
seeking counseling for mental health issues. This could be achieved using seminars and activities (e.g., counseling or mental health day), which could be held in the community in order to let them have a full picture about such matters of mental health (both the negative and positive sides). This would help eliminate distorted beliefs about mental health. Furthermore, mental health departments and those organizations that provide counseling services could cooperate together by informing citizens about the nature of counseling service for mental health issues. For example, a television program could be made talking about the procedures involved in offering assistance and the ability of recovered patients (from mild to severe disturbance) to rejoin the community. Narrowing down the distance between the world of normality (general population) and the world of divergence (minor population-patients) might also help.

Moreover, Lee (2004) has suggested offering counseling training or courses (validated by the government) to general medical doctors. Family doctors have been found to be the first source for people with mental health concerns for seeking assistance. Thus, strengthening family doctors' counseling techniques would allow them to evaluate patients' situations and provide them with assistance. For more serious issues, family doctors could act as a bridge between patients and specialized professionals to ensure that patients receive adequate assistance effectively in addition to preventative care (i.e., recognizing that patients have the potential to develop mental health problems and become victims due to the labeling effect).

\section{References}

Andrews, G., Hall, W., Teesson, M., \& Henderson, S. (1999). National Survey of Mental Health and Wellbeing Report 2: the Mental Health of Australians. Common wealth of Australia.

Bergin, A.E., \& Garfield, S.L. (1994). Handbook of Psychotherapy and Behavior Change (4th ed.). Canada: Wiley.

Boldero, J., \& Fallon, B. (1995). Adolescent help-seeking: what do they get help for and from whom? Journal of Adolescence, 18(2), 193- 209. http://dx.doi.org/10.1006/jado.1995.1013

Bond, M.H., \& Hwang, K.K. (1986). The social psychology of Chinese people. In: Bond, M.H. (Ed.), The Psychology of the Chinese People, pp. 213-266. Oxford: Oxford University Press.

Bowman, B., \& Payne, J. (2011). A profile of students receiving counseling services at a university in post-apartheid South Africa. Journal of Child and Adolescent Mental Health, 23(2), 143-153. doi: $10.2989 / 17280583.2011 .634544$

Brooks, G. R. (1998). A new psychotherapy for traditional men. San Francisco: Jossey-Bass.

Carlton, P.A., \& Deane, F.P. (2000). Impact of attitudes and suicidal ideation on adolescents' intentions to seek professional psychological help. Journal of Adolescence, 23(1), 35-45. doi: 10.1006/jado.1999.0299

Chang, H. (2008). Help-seeking for stressful events among Chinese college students in Taiwan: Roles of gender, prior history of counseling, and help-seeking attitudes. Journal of College Student Development, 49(1), 41-51. doi: 10.1353/csd.2008.0003 
Cohen, J. (1992). A power primer. Psychological bulletin, 112(1), 155-159.

Cooper, A. E., Corrigan, P. W., \& Watson, A. C. (2003). Mental illness stigma and care seeking. Journal of Nervous and Mental Disease, 191(5),339-341. Retrieved from http://www.ncbi.nlm. nih.gov/pubmed/12819554

Corrigan, P. (2004). How stigma interferes with mental health care. American psychologist, 59(7), 614. doi: 10.1037/0003-066X.59.7.614

Deane, F. P., \& Chamberlain, K. (1994). Treatment fearfulness and distress as predictors of professional psychological help-seeking. British Journal of Guidance \& Counselling, 22(2), 207-217. doi:10.1080/03069889400760211

Deane, F. P., \& Todd, D. M. (1996). Attitudes and perceived likelihood of seeking professional help for personal problems or suicidal thinking. Journal of College Student Psychotherapy, 10(3), 45-59. http://dx.doi.org/10.1300/J035v10n04_06.

Diala, C., Muntaner, C., Walrath, C., Nickerson, K.J., LaVeist, T.A., \& Leaf, P.J. (2000). Racial differences in attitudes toward professional mental health care and in the use of services. American Journal of Orthopsychiatry, 70(4), 455-464. doi: 0.1037/h0087736

Eisenberg, D., Golberstein, E., \& Gollust, S. E. (2007). Help-seeking and access to mental health care in a university student population. Medical care, 45(7), 594-601. doi:10.1097/ MLR.0B013e31803bb4c1

Erikson, E.H. (1995). A Way of Looking at Things: Selected Papers, 1930-1980. W.W. Norton \& Company.

Fischer, E. H., \& Farina, A. (1995). Attitudes toward seeking professional psychological help: A shortened form and considerations for research. Journal of College Student Development, 36(4), 368-373.

Fisher, J. S., Goff, B. A., Nadler, A., \& Chinsky, J. M. (1988). Social psychological influences on help seeking and support from peers. In B. H. Gottlieb (Ed.), Marshaling social support: Formats, processes, and effects (pp. 267-304). Newbury Park, CA: Sage.

Flisher, A. J., De Beer, J. P., \& Bokhorst, F. (2002). Characteristics of students receiving counselling service at the University of Cape Town, South Africa. British Journal of Guidance and Counselling, 30(3), 299-310. doi: 10.1080/030698802100002000

Goldberg, L. R. (1993). The structure of phenotypic personality traits. American Psychologist, 48(1), 26-34. doi:10.1037/0003-066X.48.1.26

Goldberg, L. R. (1999). A broad-bandwidth, public domain, personality inventory measuring the lower-level facets of several Wve-factor models. In I Mervielde, I. Deary, F. De Fruyt, \& F. Ostendorf(Eds.), Personality psychology in Europe (Vol. 7, pp. 7-28). Tilburg, The Netherlands: Tilburg University Press

Greenson, R. R. (1987). The technique and practice of psychoanalysis. Madison, Wl: International University Press.

Hair, J.F., Anderson, R.E., Tatham, R.L. and Black, W.C. (1998), Multivariate Data Analysis, fifth ed. Prentice Hall, Upper Saddle River, NJ.

Hassan, H. D. (2008). Iran: Ethnic and religious minorities. Retrieved from https://fas.org/sgp/crs/ mideast/RL34021.pdf

Harman, H. H. (1960), Modern Factor Analysis. Chicago: University of Chicago Press

Harris, S. M., Dersch, C. A., \& Mital, M. (1999). Look who's talking: Measuring self-disclosure in MFT. Contemporary Family Therapy: An International Journal, 21 (3), 405-415. doi: 10.1023/A:1021968517320 
Hinderaker, D.J. (2003). College Student Mental Health and Use of Counseling Center Services. Master of Social Work Clinical Research Papers. Paper 190. http://sophia.stkate.edu/msw_ papers/190

Ho, D.Y.H. (1976). On the concept of face. American Journal of Sociology, 81(4), 867-884. doi: $10.1086 / 226145$

Jourard, S.M. (1964). The transpersonal self. New York: Van Nostrand.

Lee, W.K. (2004). The Hong Kong citizens' attitudes and behaviors about seeking help for the emotional problems. Research fund by Hong Kong Primary Care Foundation (HKPCF) and presented in Hong Kong

Li, J., Wang, L., \& Fischer, K. (2004). The organization of Chinese shame concepts. Cognition \& Emotion, 18(6), 767-797. doi:10.1080/02699930341000202

Lin, Y. (2002). Taiwanese university students' conceptions of counseling. Journal of Contemporary Psychotherapy, 31(3), 199-211. doi: 10.1023/A:1013968105377

Kahn, J.H., \& Hessling, R.M. (2001). Measuring the tendency to conceal versus disclose psychological distress. Journal of Social and Clinical Psychology, 20(1), 41-65. doi: 10.1521/ jscp.20.1.41.22254

Keith-Lucas, A. (1994). Giving and taking help (2nd ed.). St. Davids, PA: North American Association of Christian Social Workers

Kelly, A.E. (1998). Clients' secret keeping in outpatient therapy. Journal of Counseling Psychology, 45(1), 50-57. doi: 10.1037/0022-0167.45.1.50

Kim, B. S. K. (2007). Adherence to Asian and European American Cultural Values and Attitudes Toward Seeking Professional Psychological Help Among Asian American College Students. Journal of Counseling Psychology, 54(4), 474-480. doi: http://dx.doi.org/10.1037/0022-0167.54.4.474

Komiya, N., Good, G. E., \& Sherrod, N.B. (2000). Emotional openness as a predictor of college Students' attitudes toward seeking psychological help. Journal of Counseling Psychology, 47(1), 138-143. doi: 10.1037/0022-0167.47.1.138

Kushner, M.G., \& Sher, K.J. (1989). Fear of psychological treatment and its relation to mental health service avoidance. Professional Psychology: Research and Practice, 20(4), 251-257. doi: $10.1037 / 0735-7028.20 .4 .251$

Masuda, A., Anderson, P. L., Twohig, M. P., Feinstein, A. B., Chou, Y.-Y., Wendell, J. W., \& Stormo, A. R. (2009). Help-seeking experiences and attitudes among African American, Asian American, and European American college students. International Journal for the Advancement of Counseling, 31(3), 168-180. doi:10.1007/s10447-009-9076-2

Meehan, P.J., Lamb, J.A., Saltzman, L.E., \& O’Carroll, P.W. (1992). Attempted suicide among young adults: progress toward a meaningful estimate of prevalence. American Journal of Psychiatry, 149(1), 41-44. doi: 10.1176/ajp.149.1.41

McCarthy, J. (2005). Individualism and Collectivism: What do they have to do with counseling? Journal of Multicultural Counseling and Development, 33(2), 108-117. doi: 10.1002/j.21611912.2005.tb00009.x

McCrae, R. R., \& Costa, P. R. (2008). The five-factor theory of personality. In O. P. John, R. W. Robins, L. A. Pervin, O. P. John, R. W. Robins, L. A. Pervin (Eds.), Handbook of personality psychology: Theory and research (3rd ed.) (pp. 159-181). 
McCrae, R. R., \& John, O. P. (1992). An introduction to the five-factor model and its applications. Journal of Personality, 60(2), 175-215. doi:10.1111/j.1467- 6494.1992.tb00970.x

Morrow, D., Worthington, E.L., \& McCullough, W.E. (1993). Observers' perceptions of a counselor's treatment of a religious issue. Journal of Counseling \& Development, 71(4), $452-$ 456. doi: 0.1002/j.1556-6676.1993.tb02664.x

Morton, T. L. (1978). Intimacy and reciprocity of exchange: A comparison of spouses and strangers. Journal of Personality and Social Psychology, 36(1), 72-81. doi: 10.1037/0022-3514.36.1.72

Narikiyo, T. A., \& Kameoka, V. A. (1992). Attributions of mental illness and judgments about help seeking among Japanese-American students. Journal of Counseling Psychology, 39(3), 363369. doi: 10.1037/0022-0167.39.3.363

Pearson,V. (1993). Families in China: An undervalued resource for mental health. Journal of Family Therapy, 15(2), 163-185. doi: 10.1111/j.1467-6427.1993.00752.x

Pennebaker, J.W. (1997). Opening up: The healing power of expressing emotions. New York: Guilford.

Pew Research Center, (2016). Buddhists, Retrieved from http://www.pewforum.org/2012/12/18/ global-religious-landscape-buddhist/

Pipes, R.B., Schwarz, R., \& Crouch, P. (1985). Measuring clients fears. Journal of Counseling and Clinical Psychology, 53(6), 933-934. doi: 10.1037//0022-006X.53.6.933

Robbins, S., \& Judge, T.A. (2014). Organizational Behavior (16ed.), Pearson

Santrock, J. (2015). Life-Span Development (15ed.), McGraw Hill.

Sekaran, U., \& Bougie, R. (1992). Research Methods for Business: A Skill Building Approach, John Willey and sons Inc. New York.

Seligman, M. E. P., \& Csikszentmihalyi, M. (2000). Positive psychology: An introduction. American Psychologist, 55(1), 5-14. http://dx.doi.org/10.1037/0003-066X.55.1.5

Sennet, J., Finchilescu, G., Gibson, K., \& Strauss, R. (2003). Adjustment of black students at a historically white South African university. Educational Psychology, 23(1), 107-116. doi: $10.1080 / 0144341022000022988$

Sibicky, M., \& Dovidio, J. F. (1986). Stigma of psychological therapy: Stereotypes, interpersonal reactions, and the self-fulfilling prophecy. Journal of Counseling Psychology, 33(2), 148. doi: 10.1037/0022-0167.33.2.148

Stefl, M. E., \& Prosperi, D. C. (1985). Barriers to mental health service utilization. Community Mental Health Journal, 21(3), 167-177. doi: 10.1007/BF00754732

Tavakoli, M. (2013). Content and Style of Advice in Iran and Canada/Le Contenu et la style de conseil en Iran et Canada. Canadian Journal of Counselling and Psychotherapy, 47(2), 299-311. Retrieved from http://cjcrcc.ucalgary.ca/cjc/index.php/rcc/article/viewFile/2513/2482

Teyber, E. M. (2005). Interpersonal process in psychotherapy: An integrative model (5th ed.). Belmont, CA: Brooks/Cole.

Wamser, R., Vandenberg, B., \& Hibberd, R. (2011). Religious fundamentalism, religious coping, and preference for psychological and religious treatment. The International Journal for the Psychology of Religion, 21(3), 228-236. doi: 10.1080/10508619.2011.581582

Washington Post (2013). A surprising map of where the world's atheists live. Retrieved from https:// www.washingtonpost.com/news/worldviews/wp/2013/05/23/a-surprising-map-of-where-theworlds-atheists-live/?utm_term=.ec2ecb4ec44f 
Worthy, M., Gary, A.L., \& Kahn, G.M. (1969). Self-disclosure as an exchange process. Journal of Personality and Social Psychology, 13(1), 59-63. doi: 10.1037/h0027990

Vogel, D. L., Wade, N. G., \& Haake, S. (2006). Measuring the self-stigma associated with seeking psychological help. Journal of Counseling Psychology, 53(3), 325-337. doi:10.1037/00220167.53.3.325

Vogel, D. L., \& Wei, M. (2005). Adult attachment and help-seeking intent: The mediating roles of perceived social support and psychological distress. Journal of Counseling Psychology, 52(3), 347-357. doi: : 10.1037/0022-0167.52.3.347

Vogel, D. L., \& Wester, S. R. (2003). To seek help or not to seek help: The risk of self-disclosure. Journal of Counseling Psychology, 50(3), 351-361. http://dx.doi.org/10.1037/0022-0167.50.3.351

Vogel, D. L., Wester, S. R., \& Larson, L. M. (2007). Avoidance of counseling: Psychological factors that inhibit seeking help. Journal of Counseling \& Development, 85(4), 410-422. doi: 10.1002/ j.1556-6678.2007.tb00609.x

Williams, K. E., Chambless, D. L., \& Ahrens, A. H. (1997). Are emotions frightening? An extension of the fear of fear concept. Behaviour Research and Therapy, 35(3), 239-248. doi:10.1016/ S0005-7967(96)00098-8

Yang, K.S. (1995). Chinese social orientation: an integrative analysis. In: Lin, T.Y., Tseng, W.S., Yeh, E.K. (Eds.), Chinese Societies and Mental Health, pp. 19-39. Hong Kong: Oxford University Press.

Yang, L. H., Phelan, J. C., \& Link, B. G. (2008). Stigma and beliefs of efficacy towards traditional Chinese medicine and Western psychiatric treatment among Chinese-Americans. Cultural Diversity \& Ethnic Minority Psychology, 14(1), 10-18. doi: 10.1037/1099-9809.14.1.10.

Young, C. (2009). The CORE-OM intake norms of students attending a South African university counselling service: A comparison with UK counseling service data. British Journal of Guidance \& Counselling, 37(4), 473-483. doi: 10.1080/03069880903161377 